\title{
La historia de los intelectuales en España
}

\author{
Paul Aubert \\ Aix-Marseille Université- Telemme CNRS 7303. \\ Maison Méditerranéenne des Sciences de l'Homme (MMSH) \\ 5, rue du Château de l'Horloge \\ BP 647 - 13094 Aix-en-Provence Cedex 2 \\ aubert@mmsh.univ-aix.fr
}

Resumen: Tras la generación que hizo posible la Primera República, los intelectuales, con la Segunda, dispusieron brevemente en España del aparato de estado. Su intervención en la vida política, su relación con el poder y, luego, su acceso a las responsabilidades del estado constituyen una clave para entender la historia nacional a lo largo del primer tercio del siglo xx. Su historia está unida, pues, a la de la nación.

Precisar lo que estaba en juego y explicar las modalidades, las etapas y el alcance de ese fenómeno implica un renacimiento y una renovación de la historia política y cultural. Solo desde hace poco tiempo se ha considerado que dicha historia era la de un fenómeno colectivo cuyo estudio acabó constituyendo una disciplina. Antes de exponer cuáles fueron estos nuevos enfoques parece oportuno recordar en qué consistió dicha historia. Tras un breve estado de la cuestión, el artículo, redactado según el enfoque de «balance y perspectiva», esboza una serie de propuestas metodológicas.

Palabras Clave: historia cultural; historia política; intelectuales; Segunda República

\section{The History of Intellectuals in Spain}

Авstract: After the generation that produced the First Spanish Republic, intellectuals briefly controlled the state apparatus during the Second Spanish Republic. Their engagement in political life, relationship to power, and subsequent assumption of state duties provide a key to understanding Spain's national history over the first third of the twentieth century. In

Aubert, Paul (2019), «La historia de los intelectuales en España». Cercles. Revista d'Història Cultural, 22, 81-109. ISSN: 1139-0158. ISSN-e: 1699-7468. DOI: 10.1344/cercles2019.22.1003. Data de recepció: 19/3/2019. Data d'acceptació: 5/5/2019. 
short, the history of Spain's intellectuals is tied inextricably to the history of the nation.

To define what was at stake and explain the modes, stages and extent of the phenomenon involves a revival and renewal of political history and cultural history. Only recently has this history been regarded as a collective phenomenon, whose study ultimately has become a discipline in its own right.

Prior to presenting the new approaches, it is appropriate to recall what this history entailed. After a brief examination of the current state of play, the paper outlines a set of methodological proposals drawing on the "balance and perspective" approach.

Keywords: cultural history, political history, intellectuals, Second Spanish Republic

«España es el único país en que los intelectuales se ocupan de política inmediata", escribía, orgulloso, Ortega y Gasset en 1927. La fecha importa mucho porque, en I940, confesaba que el intelectual que en su país lo era todo — pues redactaba el relato nacional — ya no era nada.

Tras la generación que hizo la Primera República, los intelectuales dispusieron brevemente en España del aparato de estado. Su intervención en la vida política, su relación con el poder y, luego, su acceso a las responsabilidades del estado constituyen una clave para entender la historia de España a lo largo del primer tercio del siglo xx. En ningún país europeo desempeñaron, sin duda, un papel tan importante, cuyo estudio preconizó Antonio Gramsci. ${ }^{I} \mathrm{Al}$ mismo tiempo, aunque no pudo, o no supo (o no quiso), hacer del caso Ferrer su Affaire Dreyfus, el intelectual catalán va cobrando importancia en la crítica de la política nacional. Alomar, Domingo publican también en Madrid. Y el intelectual español nace en Barcelona

I Antonio Gramsci, Cahiers de prison, cahier 9, París, Gallimard, I983, pp. 505-506.

Cercles. Revista d'Història Cultural, 22 (2019), 81-109.

ISSN: 1139-0158. ISSN-e: 1699-7468. DOI: 10.1344/cercles2019.22.1003. 
con el caso Corominas con cronología y modalidades parecidas a las de su homólogo francés.

Su historia está unida, pues, a la de la nación. Precisar lo que estaba en juego y explicar las modalidades, las etapas y el alcance de ese fenómeno implica un renacimiento y una renovación de la historia política y historia cultural. Solo desde hace poco tiempo se ha considerado que dicha historia era la de un fenómeno colectivo cuyo estudio acabó constituyendo una disciplina. Antes de exponer cuáles fueron estos nuevos enfoques parece oportuno recordar en qué consistió dicha historia.

\section{Objeto de estudio}

Habida cuenta de la limitada importancia de la burguesía y del proletariado urbano, solo una élite culta traduce las nuevas aspiraciones políticas. ¿Qué pueden los intelectuales? ¿Qué poder es el suyo para que les teman los gobernantes, para que el público los solicite o los acuse y condene su indiferencia o su febrilidad? Se creyó, siguiendo a Ortega y Gasset, que su vocación era constituirse en clase rectora a lo largo del primer tercio del siglo xx.

El mayor papel de los intelectuales en España, un país periférico en la Europa desarrollada, tiene cierto paralelismo con la decadencia del Parlamento; hasta tal punto que se acaban confundiendo con la conciencia y la representación nacional. Por la constancia de su protesta y su omnipresencia en la prensa y en las manifestaciones públicas, crean un clima ideológico favorable a la Primera y, luego, a la Segunda República, cuyo advenimiento piensan comentar. ¿Estaban convencidos de que encarnaban al país real? Su compromiso público recuerda que la cultura española conoció una edad de oro, pero también prueba que a la sociedad le faltaba cohesión y que padecía un déficit democrático, hasta el punto de recurrir a los sabios de la tri- 
bu. El papel crítico de los intelectuales fue útil para la democracia, pero no se sabe si pudieron ir más lejos cuando el pueblo, que querían que entrara en el Parlamento, se masificó y salió a la calle.

Este estudio se articula en torno a la emergencia de unos expertos (desde el discurso legitimador hasta el reconocimiento social), y tendría que desarrollarse con una interrogación en torno a la noción de compromiso en cuanto que el perito o el intelectual pretende ostentar el monopolio de la palabra autorizada y del discurso social. Más que a una tipología de los actores, se dedicó mayor atención a las modalidades y al balance de su acción en el seno de las instituciones culturales y sociales, sin menoscabar el análisis de sus relaciones con el movimiento obrero. Vertebran esta investigación las relaciones entre lo público y lo privado, y el estado y la nación. Después de analizar el proceso de emergencia, de formación y de legitimación de las élites (que a veces pasa por el estudio de su memoria), así como sus estrategias internas según dos perspectivas: su participación en el aparato de estado y la aparición de élites profesionales, se ha estudiado su papel en la vida pública y su intervención en el debate social y en la acción política, otorgando una atención particular a las modalidades de esta estrategia externa y a lo que estaba en juego.

Se puede echar mano de dos definiciones de los intelectuales - la histórica considera que el nacimiento del intelectual es fruto de la autodefinición de un grupo que interviene en el campo político en nombre de la fama adquirida en el ejercicio del oficio de escritor o de científico de sus componentes (con el Affaire Dreyfus en Francia y con el caso Corominas en España), mientras la sociológica hace hincapié en la presencia creciente de unos trabajadores intelectuales que reproducen un saber práctico y que ya no encuentran el lugar que les corresponde en la sociedad-. La primera es más interesante porque obliga a ver lo que hicieron estos hombres al reivindicar esta función frente al acontecimiento, y no se contenta con explorar los matices conceptuales según los distintos momentos.

Cercles. Revista d'Història Cultural, 22 (2019), 81-109. ISSN: 1139-0158. ISSN-e: 1699-7468. DOI: 10.1344/cercles2019.22.1003. 
Una de las originalidades españolas reside en la emergencia precoz de una vocación de las élites intelectuales - una minoría dentro de una minoría alumbrada que se expresa en un país de cultura escrita poco desarrollada - a ejercer un papel dirigente y normativo.

Tras haber deseado la reforma social y la secularización del saber (propia del liberalismo), las élites definieron, a principios del siglo xx, el estado-nación, y emprendieron la construcción del estado liberal. Su peso social fue aumentando y los intelectuales dejaron de intervenir puntualmente en nombre del derecho o de la justicia para definir un proyecto (la democratización) y dotarse de un programa (la república). Cabe preguntarse si en España, como en la Europa mediterránea, el papel creciente de estas élites culturales palió la carencia de cuadros administrativos o si desempeñó una función innovadora en la orientación de la acción pública.

Entre I875 y 1917, los intelectuales españoles procuraron provocar una crisis de conciencia en los medios políticos para sacar al país del marasmo y convertirlo en una nación moderna. Luego, entre I9I7 y I936, cuando adquirieron una mayor importancia las cuestiones sociales, los intelectuales desempeñaron un papel cada vez más activo, pero el afianzamiento de las organizaciones de masas (sindicatos y partidos obreros) les obligó a revisar las modalidades de su acción, es decir, a seguir siendo los tutores del pueblo o a proyectarse en la acción junto a militantes provenientes de los partidos políticos y de los sindicatos.

Fue durante la primera guerra mundial cuando esta intervención se estructuró y se hizo permanente. Estos emergieron como actores políticos cuando el sistema de la Restauración se confrontó a su propio bloqueo y antes de que se llegara a pensar que las soluciones o las vías alternativas estaban fuera del sistema político (tras el fracaso de dos intentos, conservador y liberal, de solución interna: las experiencias de Maura y de Canalejas). Ya no se trataba de un movimiento de protesta intermitente, sino de una acción continua y pertinaz que se 
dotaba de nuevas vías de acción y disponía de nuevos medios de expresión.

Si se pudo hablar en la España de 193I de una «República de intelectuales», como ocurrió unos años antes en Francia, donde se denominó «República de profesores», fue no solo para calificar la omnipresencia de hombres de cultura en el debate político nacional, sino porque nunca se dio tanta importancia a la instrucción pública, a la difusión de la cultura o a la investigación universitaria. Naturalmente, no cabe olvidar que lo que estuvo en juego fue más social que intelectual, y que no se pueden buscar tan solo las causas de la guerra civil de 1936 en una aporía del pensamiento, olvidando otros factores como la resistencia de la Iglesia, de los terratenientes o de parte del patronato.

A partir de 1934, empezó otra historia que no exigía un compromiso político, sino una elección frente a la revolución y la contrarrevolución, y la amenaza de una guerra civil. La índole de este compromiso cambió con el conflicto civil. La guerra significó el destronamiento del intelectual, según Ortega y Gasset, ya que este, después de haber creído que lo era todo (era quien escribía el relato nacional, si no la historia), acabó por no ser nada. Los que se negaron a transformarse en militantes al servicio de un campo tomaron el camino del exilio. No tardaron en comprobar que estaban condenados al olvido si perdían el contacto con los intelectuales del interior.

Un debate reciente entre los herederos de José Luis López Aranguren y los de Julián Marías ha planteado de nuevo una cuestión molesta sobre la actitud de algunos intelectuales durante el franquismo y, por consiguiente, sobre la manera de estudiarla. Mientras que la geografía del exilio se iba poblando de escritores y de pensadores, en España iban apareciendo intelectuales «falangistas» dispuestos a construir el nuevo estado de Franco sobre fundamentos neo-tomistas. Llegaron a autodefinirse unos años después como «falangistas liberales», y algunos de ellos adquirieron una dignidad real. Cabe

Cercles. Revista d'Història Cultural, 22 (2019), 81-109.

ISSN: 1139-0158. ISSN-e: 1699-7468. DOI: 10.1344/cercles2019.22.1003. 
revisar su acción y su obra en la preparación de lo que se dio en llamar la transición hacia la democracia, preguntándose en qué medida y hasta qué punto contribuyeron a facilitarla, sin dejar de comprobar que hicieron más opaco el camino que trazaron, hasta el punto de aparecer solo como los liberales que llegaron a ser.

Numerosos son, en efecto, estos disidentes de la década de 1960 que se formaron en el seno de la Falange, cuando no en las esferas del poder, como Pedro Laín Entralgo, Joaquín Ruiz Jiménez o el mismo Aranguren. Volver sobre ese episodio hace correr el riesgo de olvidarse de obviar su evolución y el papel que desempeñaron a favor de la democratización del régimen. De tal manera que en nombre del consenso que presidió la reconstrucción de la España democrática durante un periodo llamado Transición (cualidad que solo se puede aducir a posteriori desde el punto de llegada), se echó un velo púdico sobre su comportamiento juvenil. Pero la acción de tales intelectuales católicos, antes y después de la guerra civil, acabó interesando a los historiadores.

A lo largo de la década de I980, se comprobó una dilución de la función y una desvirtuación del término. Todavía había intelectuales que pretendían criticar el poder o aconsejar al Rey y otros más protestatarios, que firmaban manifiestos (la aparición del nuevo intelectual no implicaba la desaparición del intelectual tradicional); pero la firma de unos escritores reconocidos fue seguida por la de estrellas del music-hall. Otra evolución de la función crítica del intelectual la ilustra el magisterio que ejercieron, en las columnas de algunos grandes periódicos, tres o cuatro historiadores, a quienes se les encargaba una crónica regular para comentar la actualidad a partir de una puesta en perspectiva histórica, cuando sus mayores no pasaron de un papel de testigos de un pasado reciente ocultado por la dictadura franquista. Pero queda una cuestión actual: la presencia del intelectual en la sociedad de consumo y, por consiguiente, su conversión en intelectual mediático, cuando no auxiliar del periodista. 
Los intelectuales se habían asignado tres fines: recuperar el pasado sustraído o perdido, luchar por la libertad y dibujar un futuro. Ni el resurgir de la cultura liberal ni la homologación de la herencia del exilio bastaban. El diálogo con los niños del interior (cuando hijos de vencedores y vencidos empezaron a compartir reivindicaciones y a firmar conjuntamente manifiestos) y el reencuentro parcial con el exilio hicieron fracasar muy pronto las veleidades franquistas de refundar la historia. Les tocaba a los intelectuales asignar un sentido a esta dialéctica inconclusa y hacer funcionar un estado todavía indefinido, sin olvidar que la Constitución es un medio y no un fin, ni que: «la democracia es el enigma resuelto de todas las constituciones». No pueden confundirse la ley suprema y el juego político que esta propicia.

Más que el comentario sobre la misión del intelectual, se impuso la evocación de su desaparición, o más bien una especie de distanciamiento que haría de él tan solo un observador crítico — «vigilante de los vigilantes», diría Aranguren ${ }^{3}$ - , aunque lo que se tomó por su muerte solo fuera su silencio. Pues ya no perseguía ninguna verdad absoluta en nombre de un sujeto universal, como el intelectual católico, cuando quiso contrarrestar las pretensiones del intelectual liberal o socialista, ni ningún deseo de ver triunfar una revolución. ${ }^{4}$ Tampoco aspiraba a ejercer el poder ni a suplantar a los políticos. Esta coyuntura corresponde, pues, al fin de los viejos maestros, a la liquidación de los grandes relatos 5 y a la necesidad de unos observadores críticos que asumen los principios constitutivos de la sociedad democrática: este cambio en los comportamientos sociales también

2 Karl Marx, Critique du droit politique hégelien. París, Éditions Sociales, 1976, p. 68.

3 José Luis López Aranguren, "El intelectual. La vigilancia de la vigilancia», El País, 16 de julio de 1976.

4 Congreso internacional de intelectuales y artistas. Valencia, Generalitat valenciana, I987, t.I, p. 44.

5 Véase, Santos Juliá, Historias de las dos Españas. Madrid, Taurus, 2004.

Cercles. Revista d'Història Cultural, 22 (2019), 81-109.

ISSN: 1139-0158. ISSN-e: 1699-7468. DOI: 10.1344/cercles2019.22.1003. 
fue una transición, por no decir una novedad. No obstante, para el intelectual, esta nueva actitud conllevaba el riesgo de privilegiar la comunicación aferrándose a una ficción metodológica destinada a mostrar las formas inevitables de autonomización de lo social.

\section{Estado de la cuestión}

Hasta hace unos años, la historia de los intelectuales en España se relegaba a un apartado denominado "literatura y sociedad», en el que a menudo se evocaba su colaboración en alguna que otra revista. Luego se enfocó en función de una encuesta sobre la percepción de la decadencia nacional o la voluntad regeneradora. A partir de ese momento, la convergencia de algunos puntos de vista favorecería la revisión de la interpretación de algunas trayectorías como fue el caso de Miguel de Unamuno, Antonio Machado o Manuel Azaña.

Algunas obras nos guiaron en este empeño. Rosa Rossi, en $D a$ Unamuno a Lorca (1967), propuso un estudio socio-literario, desde la llamada generación del 98 hasta la del 27, alrededor de unos temas claves. Existían monografías del tipo «el hombre y su obra», pero escaseaban las explicaciones globales en relación con la cultura y la sociedad. Las primeras pistas las sugirieron estudios en torno a los orígenes de la sociedad liberal y la recepción del krausismo (Gómez Molleda, Cacho Viu, Gil Cremades, Elías Díaz). A mediados de la década de I970, la publicación de cuatro tesis dirigidas por Elías Díaz sobre Julián Besteiro (Emilio Lamo de Espinosa), Fernando de los Ríos (Virgilio Zapatero), Adolfo Posada (Francisco Laporta) y Manuel Sales y Ferré (Manuel Núñez Encabo) inició un proceso de rehabilitación de figuras olvidadas por el franquismo, en un momento en que se empezaba a hablar de la sociología de la cultura (J. L. Abellán).

Luego llamó la atención de los especialistas (Inman Fox, Rafael Pérez de la Dehesa) el nacimiento de los intelectuales en España 
entre el proceso de Montjuïc y la crisis de 1898 y su comportamiento en la guerra civil y, más tarde, el exilio. El vacío que quedó entre el estudio del principio y del final de la intervención de los intelectuales en la vida pública lo llenaron parcialmente biografías (que algunos eruditos «a la violeta», según decían en el siglo de las Luces, confundieron con el comentario de una cronología) dedicadas más al estudio de su pensamiento que de su acción.

El estudio del primer decenio del siglo xx se enfocó desde el estudio del populismo (Álvarez Junco, Serrano) o de las primeras armas de jóvenes escritores como Unamuno u Ortega. El siguiente se abordó en una serie de artículos monográficos o de libros dedicados a los intelectuales más importantes: Costa, Machado, Unamuno, Ortega, Marañón, Azorín, Maeztu, Pérez de Ayala, De los Ríos o Araquistáin. Por fin, la actualidad llamó la tención con efemérides y aniversarios, sobre Unamuno (1986), Marañón (1988), Antonio Machado (1989), Azaña (1990), Besteiro (I991) y Sánchez Albornoz (I993). Junto a los estudios que suscitó, a veces muy valiosos, permanecen zonas oscuras que envuelven a los intelectuales que tomaron el camino del exilio, como Luis Jiménez de Asúa o Fernando Valera.

Dos libros pioneros contrastan con tales acercamientos monográficos: Manuel Tuñón de Lara publicaba, en I970, Medio siglo de cultura española, y José Carlos Mainer, en 1975, La Edad de Plata (I902-1939)- Ensayo de interpretación de un proceso cultural. El primero ofrece una aproximación global a partir de grandes coyunturas en las que se enmarcan las corrientes ideológicas. Tuñón de Lara considera el conjunto del fenómeno cultural, así como las interacciones que unen las esencias y las disciplinas que le son consustanciales: economía, política, ideología, historia de las relaciones internacionales (que no confunde con un mero inventario de los tratados), de los influjos e imágenes recíprocos (que algunos fatuos confundieron con el temerario inventario de lo que los españoles debían a la historiografía francesa, provocando la indignación justificada de Josep

Cercles. Revista d'Història Cultural, 22 (2019), 81-109.

ISSN: 1139-0158. ISSN-e: 1699-7468. DOI: 10.1344/cercles2019.22.1003. 
Fontana), ${ }^{6}$ del movimiento obrero, de la Iglesia, de la educación, de la prensa, del ejército, de las mentalidades, de los conceptos etc., aunque no aborda la historia de la ciencia. Pero considera que no es vano querer contribuir a esta historia "histórica» de la literatura que esperaba Lucien Febvre. ${ }^{7}$ Tuñón de Lara quiso explicar lo que propició lo que se dio en llamar «la edad de plata de la cultura española» en un país minado por el analfabetismo $(40 \%)$ y la desvirtuación del régimen parlamentario. Ya no intenta medir la relación de algunas obras con la sociedad, sino recalcar su carácter profético en la formación de una visión del mundo y de una mentalidad social que explican el lento proceso de democratización de la vida política española. No se trata todavía de una sociología de la cultura, pero ya es algo más que una mera historia de las ideas. Tuñón de Lara entiende por cultura un sistema de valores propio de la sociedad española a la que dedica un estudio global, distinto del enfoque clásico a menudo limitado al recuerdo del influjo del krausismo, a la reacción que suscitó o a algunas variaciones en torno al 98, que es el de Luis Araquistáin, por ejemplo, en su libro El pensamiento español contemporáneo, publicado ocho años antes en Buenos Aires, o del estudio de Werner Kraus y Carlos Rincón (1972), que completan un balance del krausismo español, de la pedagogía liberal y un estudio de la pretendida generación del 98, por enfoques sectoriales por géneros (poesía, novela, teatro, cine) de la producción cultural que prolongan, tras un análisis de las estructuras económico-sociales, por una evaluación sociológica (clero, ejército, proletariado). Pero ya Elorza había enfocado la cuestión desde el socialismo utópico.

José Carlos Mainer, con La Edad de Plata y La Corona hecha trizas, no pretendía escribir una historia social de la literatura con-

6 Josep Fontana, La Historia después de la Historia. Barcelona, Crítica, I992, pp. II3-I26.

7 Lucien Febvre, Combats pour l'Histoire. París, Armand Colin, 1953, p. 264.

Cercles. Revista d'Història Cultural, 22 (2019), 81-109. ISSN: 1139-0158. ISSN-e: 1699-7468. DOI: 10.1344/cercles2019.22.1003. 
temporánea, pero su obra tiene la ventaja de proponer líneas interpretativas sugiriendo una historia de la sociedad, de las instituciones o de los medios de información. Por ejemplo, el desarrollo de la prensa y de las revistas no es ajeno al impulso que conoce el ensayo en el primer tercio del siglo xx. El autor plantea también la cuestión del público, de la emergencia de un reformismo burgués. Muestra, asimismo, en trabajos más recientes sobre la institucionalización de la historia literaria, cómo los románticos y los krausistas forjaron una historia literaria patriótica del pueblo español que les permitiera reconciliarse con su pasado nacional.

A menudo se suele llamar historias de la literatura a compilaciones de monografías. Sus autores prefieren analizar exclusivamente unos cuantos itinerarios individuales en vez de abordar, desde un punto de vista ideológico o semiótico (desde dentro o fuera), los cambios de perspectiva que explican las rupturas: crisis del relato objetivo y emergencia del sujeto, experimentalismo, vanguardias etc. No son muy útiles para el estudio del fenómeno de los intelectuales porque prescinden de un género que vertebra nuestra cuestión y que renació a partir de la década de i890: el ensayo. Aunando la improvisación y la autobiografía como expresión de una conciencia nacional, se estudió poco, tras la obra pionera de Juan Marichal, La voluntad de estilo. Teoría e historia del ensayismo hispánico (1957), que procura enlazar con las obras del Siglo de Oro y la Ilustración, hasta la publicación de una obra colectiva (estudio y antología) coordinada por Jordi Garcia y Domingo Ródenas (2009). El libro de Jacques Beyrie Qu'est-ce qu'une littérature nationale? (1994) plantea, desde la Edad Media hasta nuestros días, de modo teórico - aunque no dialéctico, porque no tiene en cuenta de los hechos políticos y se limita al análisis de la escritura-, el problema de las representaciones que fundan una nación, desde el paisaje hasta el recuerdo de la epopeya, la cuestión de la identidad, del territorio y del poder, en el primer estado constituido de Europa.

Cercles. Revista d'Història Cultural, 22 (2019), 81-109.

ISSN: 1139-0158. ISSN-e: 1699-7468. DOI: 10.1344/cercles2019.22.1003. 
En el ámbito de la historia de las ideas, con el influjo del krausismo hasta el anarquismo y el marxismo, las referencias son numerosas: las influencias extranjeras, desde la introducción en España de los grandes movimientos científicos, del darwinismo a la relatividad, estudiados por Diego Núñez, Thomas Glick o Rafael Chabran; o la historia de las ciencias, considerada por José Manuel Sánchez Ron, López Piñero o José Luis Peset. El estudio de las relaciones culturales, tanto a nivel diplomático como literario, preocupó más allá de la problemática de las transferencias culturales; incluyó la recepción de unos cuantos autores fundamentales, como Nietzsche (Gonzalo Sobejano, 1967) o Renan (Pérez Gutiérrez, I988), y los influjos franceses (Aubert) o alemanes (Siles). A falta de un manual sobre la historia de las ideas, se hallan instrumentos de trabajo en la obra de José Luis Abellán (5 volúmenes entre 1868 y 1992) Historia crítica del pensamiento español, que conjuga un enfoque monográfico y enciclopédico, la recuperación de autores singulares y la historia de los movimientos ideológicos (así como en la obra dirigida, en 1988, por Albert Balcells, El pensament politic català del segle XVIII a mitjan segle XX) y en la antología coordinada en 1992 por Joan Antón y Miquel Caminals, Pensamiento político en la España contemporánea (I880-I950).

\section{Cuestiones de método}

Preocupados a menudo por la cuestión del nacimiento de los intelectuales y su comportamiento durante la guerra civil (que garantiza un interés mediático), los historiadoress se esforzaron por llenar un vacío que afectaba al primer tercio del siglo xx sin superar siempre los enfoques monográficos ni los abusos del método generacional. Solo desde hace poco tiempo se han interesado por los intelectuales de derecha, cuando Charles Maurras reivindicó tal condición para sus amigos, a través de figuras belgas o suizas (González Calleja, 
González Cuevas, Juliá), o por el papel de los intelectuales catalanes (Balcells, Ucelay da Cal, Riquer, Casassas), y formularon la necesidad de remontarse hasta la revolución liberal para ver cómo el intelectual nacía con el mercado que consagró al literato, a la figura del autor tal como lo definieron Tocqueville o incluso Burke y, más recientemente, Paul Bénichou en Le Sacre de l'écrivain, para comprobar que el escritor acabó ocupando en los negocios el lugar que había dejado vacante una aristocracia decadente. Nuevos estudios muestran una preocupación por los orígenes y un reajuste que equivale a plantear la cuestión de la eventual desaparición del intelectual, que tampoco garantiza el consenso. No hace mucho se ha estudiado tal fenómeno según un enfoque global de sociología histórica, antes de intentar un acercamiento ideológico, desde la aparición de un grupo de intelectuales autodefinidos como tales, que fueron los primeros deseosos de incluir a España en el mundo moderno, hasta la transformación del estatuto del intelectual con las interrogaciones del pensamiento revolucionario marxista.

A principios de la década de 1970, ciertos autores revelaron la juventud rebelde y militante de algunos escritores consagrados, como Unamuno (Pérez de la Dehesa, Blanco Aguinaga); encontraron los artículos «socialistas» de Ortega (Malerbe), matizando los trabajos de Gonzalo Redondo y antes de la interpretación de la formación del filósofo (Elorza); y los escritos laboristas de Maeztu (Fox), con lo que se abrió una brecha en el esquema convencional.

\section{Lugares de formación}

La actitud normativa que se atribuyen los intelectuales lleva a considerar el mismo saber, es decir, la formación recibida. El análisis histórico del proceso social de escolarización y de alfabetización ocupa un lugar importante (Millán, Cuesta Escudero, Tiana, Guereña) en rela- 
ción con el estudio global del desarrollo de formas económicas, de la estructuración social, de las prácticas culturales y de los modelos políticos e ideológicos. Uno de los mayores problemas es, sin duda, la dispersión de las fuentes y la multiplicidad de los estudios locales, animados por las instituciones de las regiones autónomas. Se dedicaron numerosas monografías a los grandes educadores, como Cossío, Luzuriaga, Castillejo. Por fin, la historia de la lectura y del libro llamó la atención (Botrel y Martínez para el siglo XIX, y Martínez Rus para el xx). La historia de la universidad hizo progresos decisivos (J. L. Peset, E. Hernández Sandoica, F. Villacorta, M. Peset, J. Uría). El Ateneo de Madrid fue a la vez una tribuna y un centro cultural que llegó a ser el refugio de la oposición: el otro parlamento, en suma. Lo esencial de la historia de dicha institución es conocido: tendría que superar el inventario de los títulos de las conferencias que se pronunciaron (García Martí, Salvador, Villacorta), e imitar el estudio que dedicó Jordi Casassas al Ateneu Barcelonès, recalcando su papel en el debate ideológico y social, pues parecía más arraigado en la sociedad que el madrileño. Por fin, algunos estudios se dedicaron a la Residencia de estudiantes (Sáenz de la Calzada, Pérez Villanueva) o a la Junta para Ampliación de Estudios, que concedió becas a los estudiantes deseosos de acabar sus estudios en el extranjero (Sánchez Ron).

\section{Medios de expresión}

La prensa desempeñó un papel importante en la formación, la intervención y la circulación de las élites, porque es, a la vez, un lugar de reconocimiento y un instrumento de estrategia, órgano del poder y contrapoder. Se hizo permanente el compromiso público de los intelectuales, que Luis de Zulueta describía todavía en i9os como una fiebre intermitente. Se manifestó gracias a la prensa, hasta tal punto que la cronología de la evolución de la prensa (aparición de crónicas, 
creación de revistas) se confunde con la del combate de los intelectuales. La colaboración periodística o la creación de un periódico son, para estas élites intelectuales, medios de afirmarse y proponerse como guías. Su acción pudo beneficiarse de una red y desarrollar modelos sociales.

A principios de siglo, además de una tribuna, muchos intelectuales disponían de una crónica. Hablaban en los mítines o en los ateneos, pero el texto de su discurso se transcribía mal que bien en la prensa. La expresión escrita tomó el relevo de la expresión oral. Su colaboración regular transformó a menudo a estos periodistas en intelectuales, o contribuyó a que se crearan como tales con el recuerdo de estas relaciones ambiguas, porque también es cierto que el periódico hace al intelectual de la misma manera que el intelectual hace al periódico. A mediados de la década de i9ıo, disponían de órganos de prensa más específicos: Los Lunes de El Imparcial, España, El Sol, Nueva España, Crisol, Leviatán. Su producción periodística se hizo cada vez más abundante: los intelectuales españoles dieron a conocer su obra tan solo mediante colaboraciones periodísticas (los casos de Azorín o de Unamuno, autores con más de cinco mil artículos, son excepcionales).

La progresión cuantitativa de los trabajos sobre la prensa de los siglos XIX y XX se acompañó de un cambio cualitativo, que permitió a ciertos investigadores superar el inventario o la mera descripción de los periódicos para dedicarse al estudio de la evolución de su infraestructura (Desvois, Cabrera, Elorza), de su ideología (Botrel, Hibbs-Lissorgues, Desvois, Aubert), antes de llevar a cabo una historia del periodismo (Desvois, Seoane, Sáiz, Fernández Sebastián, Fuentes, Aubert; dossier dedicado en 1979 en la prensa catalana entre 1900 y 1966 (Guillamet en L'Avenç). Últimamente, el gremio de los historiadores (Pasamar, Peiró, o el poco fidedigno diccionario de la RA de la Historia) se ha estudiado a veces desde un enfoque prosopográfico.

Cercles. Revista d'Història Cultural, 22 (2019), 81-109.

ISSN: 1139-0158. ISSN-e: 1699-7468. DOI: 10.1344/cercles2019.22.1003. 
Se desarrollaron estudios coyunturales o sectoriales sobre la prensa católica (García Escudero, Guasch Borrat, Hibbs-Lissorgues), obrera (Castillo, Pérez Ledesma), militar (Vanaclocha) o sobre los efectos de la propaganda extranjera (Montero, Aubert) o la crisis papelera (Desvois, Cabrera, Aubert). Se consagraron varios estudios a la censura desde principios de siglo hasta la primera guerra mundial, la dictadura de Primo de Rivera y el franquismo (Del Valle, Almuiña, Aubert, Desvois, Sinova). También progresó nuestro conocimiento del gremio de los periodistas gracias a los análisis prosopográficos (el catálogo de López de Zuazo y Algar) y a la publicación de memorias de periodistas tales como Corpus Barga, César González Ruano o Rafael Cansinos-Assens, así como del testimonio de Antonio Espina). Sobre las revistas se llevaron a cabo numerosos estudios globales (Osuna, Mainer, Tuñón de Lara, Molina, índice de Pilar Celma Valero).

El intelectual adquirió una identidad procurando modelar la opinión; los periódicos, cuyas columnas monopolizó, llegaron a ser sus órganos de expresión y los vectores de su acción pública. Esta cambió el estatuto del intelectual por el sufragio universal. Legitimó su acción, pero hizo de él un político a quien hay que juzgar como tal.

\section{Vías de acción}

Son numerosos los trabajos sobre los partidos políticos extradinásticos que acogen a los intelectuales: sobre el PSOE (Ralle, Elorza, Gillespie, Juliá), el Partido radical (Ruiz Manjón, Álvarez Junco), el Partido reformista (Suárez Cortina), Acción Republicana, el partido de Manuel Azaña (Espín), la Agrupación al servicio de la República dirigida por Ortega (Márquez Padorno). Se halla en ellos una serie de informaciones necesarias para entender el papel de algunos intelectuales en su creación y sobre las relaciones que mantuvieron lue- 
go, incluso cuando algunos pensaron en fundar un partido de intelectuales. También son útiles para su estudio los libros que analizan el sistema de partidos siguiendo una óptica de ciencia política cuyas presuposiciones superan el marco de nuestra reflexión.

Son la manifestación pública y el mitin los que dan su carácter simbólico al compromiso de los intelectuales. Pero este se revela también en los homenajes y banquetes, con su firma al pie de los manifiestos — que son, a la vez, el prólogo y la justificación de su acción-, por la justicia y el derecho, contra la represión y por la amnistía, a favor de los aliados, de la democracia o de la república. Con el carácter cívico que atribuyen a la celebración de algunas efemérides, jóvenes escritores o periodistas desconocidos llegaron a ser intelectuales. Este rito cumple, por otra parte, la doble función de oficializar el papel del intelectual en el seno de la comunicación social en su lucha por el monopolio del discurso autorizado y de legitimar un proceso que infunde coherencia a su grupo en la protesta social. Se confirma la atracción que ejerce Madrid sobre la intelectualidad que encuentra allí una formación, una tribuna y un lugar de expansión intelectual (Aubert). Permite a estos intelectuales disputar al poder el monopolio del discurso social y de la palabra autorizada. Tal rito de la expresión de protesta, tanto social como lingüística, se ha estudiado poco (Coob, Aubert, Juliá), lo mismo que la reacción antiintelectual provocada por la omnipresencia y la actitud inmodesta de algunos intelectuales (Aubert).

\section{Un planteamiento generacional}

El recurso al método de las generaciones, denominaciones mal -o demasiado bien - controladas, cuya necesidad didáctica llegó a ser, en España, tan tiránica como poco pertinente en el dominio de la historia intelectual, no logró instaurar ninguna cronología, porque

Cercles. Revista d'Història Cultural, 22 (2019), 81-109.

ISSN: 1139-0158. ISSN-e: 1699-7468. DOI: 10.1344/cercles2019.22.1003. 
las generaciones autentificadas fueron numerosas, de geometría variable y diversas índoles (literarias, científicas, políticas), capaces cada una de reivindicar a posteriori un acontecimiento fundacional (desastre del 98, centenario de la publicación del Quijote en 1905, centenario del nacimiento de Larra en 1908, guerra de 19I4, crisis de I9I7, regreso de las cenizas de Ganivet en I920, centenario de Góngora, etc.).

No obstante, la cuestión parecía zanjada: la genealogía de los intelectuales parecía establecida. Los testimonios de Luis Olariaga, Manuel Azaña, José Ortega y Gasset, y más tarde Pedro Laín Entralgo y Julián Marías — es decir, de los mismos intelectuales_-, habían impuesto algunos tópicos: la historia de los intelectuales tenía que ser generacional. Con independencia de si habían nacido en España hacia I896, con el proceso de Montjuïc, que suscitó, en términos relativos, una suerte de Affaire Dreyfus español cuya coyuntura compartía y provocaba, o allende los Pirineos, se produjo la sustantivación del adjetivo intelectual bajo la pluma de Miguel de Unamuno, por ejemplo. Según una taxonomía simplificada, las generaciones se hubieran sucedido como olas diferentes en I898, I9I4, I927, I936, I950, I960, etc. Unamuno y Ortega hubieran sido los astros de tales constelaciones (Giménez Caballero, Marías), alrededor de los cuales gravitaban estrellas menores como Maeztu, Azorín, Pérez de Ayala, Araquistáin, etc. Luego se turbó la foto y el mismo fotógrafo pareció sospechoso, pues se las arregló para decir quién de su propia promoción tenía que figurar en ella y quién debía permanecer en la sombra reservada a los epígonos.

Los enfoques «revisionistas» también llamaron la atención. Numerosos autores (Tuñón de Lara, Gonzalo Sobejano, Abellán, Fox, Blanco Aguinaga, Gullón, Mainer, Salaün, Serrano) combatieron el mito imperialista de un 98 unívoco, tanto más cuanto que a la generosa perspectiva ecuménica de Laín Entralgo (1945) le sucedió la erudita inclinación secesionista de Guillermo Díaz Plaja (195I), que distinguía 
entre modernismo y generación del 98, entre estetas e ideólogos. Así fue como, sumando influencias y filiaciones, se llegó a una galaxia institucionista-regeneracionista-modernista-noventayochista, con sus estetas verdaderos y sus ideólogos en ciernes, y cómo, a lo largo de dos decenios, los críticos siguieron agregando y excomulgando. Pero la realidad finisecular es más compleja (López Morillas, Tuñón de Lara): la percepción del fracaso de la España tradicional no se debe solo a estos jóvenes rebeldes que Azorín tuvo la habilidad de reunir en I9I3 bajo el lema del milésimo desastre. Tuñón de Lara denuncia dos mistificaciones: la primera, ideológica, en la medida en que el espíritu del 98 es para unos símbolo de liberalismo, e incluso de democracia, y, para otros, de pensamiento antiespañol; la segunda, cronológica, porque en I898, de todos los autores citados, era conocido solo Costa (con Galdós), cuya firma se hallaba en los grandes diarios, mientras Unamuno empezaba a llamar la atención.

Lo mismo que con el nacimiento histórico de los intelectuales, lo que complica el análisis es la autodefinición, así como el comentario que hacen algunos intelectuales de su propia promoción afirmando que son ajenos a ella (Olariaga, Azaña, Ortega). Ahora bien, no se van sucediendo siempre las generaciones que pueden coincidir en un mismo espacio-tiempo. Es cierto que los jóvenes que entran en liza en I906-I909 adoptan una actitud nueva: sus mayores protestaban pero no se comprometían. La nueva promoción, que toma conciencia de sí misma en la primera guerra mundial, no tiene la impresión de tomar el relevo: sigue convencida de que todo está por hacer, desde los anuarios estadísticos hasta el lenguaje político. La referencia generacional, que aparece en los títulos de las revistas, cambia. A principios de siglo, proyectan una mirada intimista sobre la realidad y designan la especificidad de un grupo que se asigna una tarea épica y solitaria: Alma española, Prometeo. A mediados del segundo decenio aparece la referencia nacional, España, y luego la internacional, Revista de Occidente. A principios de la década de I930,

Cercles. Revista d'Història Cultural, 22 (2019), 81-109.

ISSN: 1139-0158. ISSN-e: 1699-7468. DOI: 10.1344/cercles2019.22.1003. 
el título de las nuevas revistas afirma un nuevo objeto de preocupación: Política, La Calle, o una identidad colectiva, Nosotros.

Pero no dejan de cuestionar, a menudo en vano, la pertinencia del método de las generaciones al que se recurre en España. Difiere del que utilizan los historiadores franceses, que proporciona un patrón de interpretación, permite considerar el comportamiento de los intelectuales en términos de formación y de sistema de referencias comunes, y es fructífero a la hora de estudiar una institución o una ideología. En España, permitió enfocar los trabajos sobre la Institución Libre de Enseñanza, la Junta para Ampliación de Estudios o la Residencia de Estudiantes. Pero no permite ir más lejos si se procura determinar las líneas de separación ideológica que distinguen a las generaciones. El recurso a esta categoría contribuyó a una clasificación artificial de la producción literaria nacional. Pero la cuestión no puede plantearse en términos individuales, sino desde un punto de vista colectivo (definiendo "el espíritu del tiempo», Ortega prolongó la perspectiva diacrónica por una visión sincrónica), y en lo que atañe a nuestro propósito, no en términos estéticos, sino políticos: la generación del I4 (quizá la única que merece esta apelación, por haber recibido la misma formación y reaccionado frente a los mismos sucesos) no duda en «bajarse a la calle para formar el partido de la cultura», según propuso Ortega a Unamuno, mientras que la del 98 no se alejóde su autoestima de mentores poco dispuestos a atreverse en el ruedo electoral. Las obras sobre la pretendida generación del 98, considerada desde una óptica literaria, son numerosas. Constituyen una veta editorial. Dotado de tal viático, el crítico echa una mirada cruzada sobre unos cuantos temas literarios comunes a los grandes autores. Los estudios que engendró tal método no carecen de interés, pero no son siempre útiles para el estudio del fenómeno de los intelectuales. Estas generaciones sucesivas - a nadie se le ocurrió que podían coexistir - solo habrían tenido un objeto de preocupación: la identidad nacional, la esencia de España. 


\section{Del enfoque esencialista al enfoque cultural}

La reciente conmemoración de I898 ha dado lugar a la publicación de una serie de libros que cuestionan de nuevo la identidad nacional a través de los escritos de los intelectuales. Este enfoque esencialista, que considera que España tiene que rectificar el curso de su historia después de haber revelado el momento en que este bifurcó, produjo obras con un curioso título. El secreto de España (Juan Marichal, I996) reúne bajo esta denominación esotérica unas calas en la historia ideológica desde 1808 hasta 1975, para revelar aquel secreto que hubiera permitido a los españoles, a pesar de las vicisitudes históricas de los dos últimos siglos, no verse privados de conciencia nacional. Julián Marías se entrega también a un inventario de las reacciones de los escritores españoles frente al problema nacional, revisado antaño por Laín Entralgo, y al sentimiento de decadencia y de continuidad, en una serie de artículos publicados entre I97I y i998 en un libro titulado Ser español (2000), que podría retrotraer al lector al universo de Ganivet. Ya en 1976, Bernhard Schmidt confrontaba, desde una perspectiva diacrónica, los textos de distintos autores para explicar la división ideológica de los españoles en un bloque nacional-conservador y otro progresista-liberal, o el sentimiento de incomprensión y soledad que experimentaba el intelectual (El problema español de Quevedo a Manuel Azaña). Javier Varela en La Novela de España Los intelectuales y el problema de España (I999) considera que los intelectuales procuraron esclarecer un misterio, el de revelar a sus compatriotas por qué España no fue lo que hubiera tenido que ser. En pocas palabras, los intelectuales invocados — no todos están solicitadoshubieran tenido que resolver el problema de España, e incluso el de su esencia, para decir en qué sería anormal el país, evaluado según el rasero europeo. Finalmente, se echa mano de algunos mitos para explicar cómo los españoles se salvaron a pesar de todo. Ese punto de vista — afianzado por algún que otro análisis de discursos reacciona- 
rios de Balmes, Donoso, Cánovas o Vázquez de Mella - lo coronó una obra colectiva de la Real Academia de la Historia titulada España. Reflexiones sobre el ser de España (1998), que establecía normas a las que España, en retrospectiva, tendría que adecuarse, o le enseñaba la vía a seguir para recobrar su esencia perdida.

Estos autores decidieron reunir algunos retratos de españoles famosos para explicar lo que José M. ${ }^{a}$ Marco en La libertad traicionada (2000) llama «el rapto de España o la destrucción del liberalismo». Se llegó, pues, a culpar a los intelectuales de la República de lo que Víctor Ouimette llamó, en el caso de la década de I920, «el naufragio del liberalismo»: cuando llegaron a ser intelectuales por su intervención en la vida pública, estos escritores desencadenaron fenómenos que fueron incapaces de dominar. Otros autores insisten, por el contrario, en el acontecimiento que constituye la presencia de tantos escritores y artistas famosos bajo el régimen de la Restauración en una España minada por el analfabetismo y apocada por las elecciones falsificadas o la desvirtuación del parlamentarismo. Fue el caso de Andrés Trapiello en su ensayo Los nietos del Cid. La nueva Edad de Oro de la literatura española (I898-I9I4), dedicado a la pretendida generación del 98, abrumada por el problema nacional. Como tantos otros ensayistas, este autor buscó el momento simbólico que senaalaría el inicio del movimiento de salvación nacional o el origen de la guerra civil.

Los cambios políticos posteriores a 1975 permitieron rehabilitar algunas figuras olvidadas debido a la represión franquista, que quiso silenciar el nombre de los vencidos. Así es como Azaña, cuyas obras habían sido publicadas en México a mediados de la década de 1960, fue conocido en España como novelista, dramaturgo y ensayista. Asimismo, se dedicaron tesis a la obra de intelectuales que fueron presidentes de las Cortes, como el catedrático de filosofía Julián Besteiro; de derecho, como Fernando de los Ríos, o Luis Jiménez de Asúa, presidente de la comisión redactora de la Constitución de la 
Segunda República. O tesissociológicas como las de Adolfo Posada, autor del primer proyecto de dicha Constitución; o Luis Araquistáin (Bizcarrondo), político y periodista. Estas monografías situaron a algunos autores en su tiempo. Esta tarea se prosiguió hasta principios de la década de 1990 con coloquios dedicados a Salvador de Madariaga, Gregorio Marañón, Ramón María del Valle-Inclán, Antonio Machado, Manuel Azaña, Miguel de Unamuno, José Ortega y Gasset, etc.

La historia de los intelectuales durante la guerra civil fue durante mucho tiempo un estudio de los destinos suscitados por la diáspora republicana o testimonios que mezclaron a veces proyecto autobiográfico y memoria ideológica.

Centrándose en la bisagra del siglo sobre el decenio I895-1905, varios trabajos comprobaron en qué medida la crisis finisecular que marcó el principio de la crisis de hegemonía de la vieja oligarquía de la Restauración representó una ruptura en la vida cultural española. El estudio de los cambios culturales y estéticos provocados por la industrialización durante la crisis finisecular (Lily Litvak) se prolongó con el análisis de las condiciones de nacimiento de los intelectuales desde la producción cultural (Salaün-Serrano [eds.]) hasta las políticas educativas, las transformaciones culturales provocadas por la expansión urbana, la tradición y la renovación en las artes, la crisis del realismo y el acceso a la modernidad. No se trató de cambiar un I898 político por un 1900 cultural, sino de evaluar de nuevo la oposición entre ciudad y campo. El peso de la España rural lleva a preguntarse si cabe hablar de cultura agraria y de cultura urbana, o si la cultura es forzosamente urbana. Para la década de 1920, este trabajo se amplió con otro libro colectivo (Salaün-Serrano [eds.]) en el que se estudió el papel de los intelectuales en la coyuntura que va de la crisis de 1917 al advenimiento de la Segunda República (Aubert). 


\section{Nuevos enfoques: hacia una historia de los intelectuales}

En el cruce de todas las disciplinas recorridas se sitúa la historia de los intelectuales, concebida de manera tardía en España como interrogación global en torno a la aparición de un fenómeno colectivo, superando lo anecdótico y la compilación de monografías. Para finales del siglo XIX, disponemos de trabajos de referencia, desde los dedicados a la evolución política de Clarín (Lissorgues) o de Galdós (Fuentes) hasta el peso del regeneracionismo liberal (Sotelo Vázquez), que estudian, a partir de su producción periodística, las raíces ideológicas de la generación finisecular desde la revolución de I868. Otro enfoque fue el de la historia del anticlericalismo (Connely Ullman, Álvarez Junco, Suárez Cortina, La Parra, Aubert).

Joaquín Costa se estudió en el contexto de la crisis finisecular (Tuñón de Lara, Cheyne, Fernández Clemente) y en la óptica de las relaciones de la sociedad civil y el populismo (Maurice, Serrano).

Para los siguientes períodos - excepto la ingente producción en torno al sello literario del 98- se llevaron a cabo novedosos estudios sociológicos (Villacorta, Casassas). Si el recurso a la sociología y a la historia institucional o funcional permite entender la formación y la situación de los intelectuales, solo un acercamiento ideológico y político global al fenómeno los sitúa frente a lo que estuvo en juego social y políticamente.

Los estudios coyunturales se multiplicaron en torno a la actitud de intelectuales confrontados a las crisis sociales, ideológicas o políticas: 1898 (Fox, Serrano); primera guerra mundial, crisis de I9I7 (Meaker, Aubert), dictadura de Primo de Rivera (García Queipo de Llano, Aubert), década de 1920 (Aubert, Ouimette, Selva), Segunda República (Bécarud, López Campillo, Aubert, García Queipo de Llano), guerra civil (París, Juliá, Aubert), exilio (Alted), franquismo (Díaz, Marsal, Juliá, Morente, Muñoz Soro). Estos trabajos no midieron siempre el impacto de los intelectuales en dicha coyuntura y 
el influjo de esta sobre su propio itinerario. El análisis del discurso social de los intelectuales evidencia un equívoco en cuanto a la definición del titular del pacto constituyente y una esperanza infundada en la capacidad de las clases medias de hacerse cargo del cambio. El estudio de su relación con el siglo, que los sitúa frente al acontecimiento según los diversos modelos interpretativos de que dispusieron, muestra que su actitud evolucionó.

Una explicación de conjunto según un punto de vista sociológico, ideológico y político estudió, sucesivamente, para el periodo de I898 a 1936, el medio en el que se movieron los intelectuales, las ideas que los guiaron y los acontecimientos en los que estuvieron involucrados, preguntándose, por una parte, cuál era su formación, qué lugar ocupaban en la sociedad, de que órganos de expresión y de qué vías de acción dispusieron; y, por otra, cuáles eran sus ideas, qué estaba en juego y qué papel político desempeñaron y cuál era el balance de su acción (Aubert).

Nuevas pistas de investigación aparecieron junto al estudio del intelectual dreyfusard. Se dedicaron estudios recientes al nuevo intelectual de la década de 1920, lector de La trahison des clercs de Julien Benda, atento a la ética y a las cuestiones sociales. El intelectual de derechas, monárquico o fascista, de la década de 1930, que abandona el antiintelectualismo y reivindica el sustantivo intelectual, antaño gritado como un injurio, y que quiere lanzarse, también, a veces en nombre de Cristo, a «la conquista del Estado", suscitó un interés creciente (González Cuevas, Juliá, Morente, Gracia). En 1998, el recuerdo de la coyuntura crítica del siglo anterior y de la introspección literaria que originó provocaron un nuevo debate en torno a la identidad nacional, en un contexto en el que se afianzan las reivindicaciones de los nacionalismos periféricos y en que se empezó a interesarse tanto por los intelectuales catalanes (Casassas) — desde la Renaixença, a mediados del siglo xix, hasta su papel en la lucha antifranquista- como por los que encontraron en Madrid un polo de

Cercles. Revista d'Història Cultural, 22 (2019), 81-109.

ISSN: 1139-0158. ISSN-e: 1699-7468. DOI: 10.1344/cercles2019.22.1003. 
atracción que les confería un estatuto, dotándoles de un público, de medios de expresión, de vías de acción, e incluso de sucesos que suscitar o comentar. En la España descentralizada de los primeros tres cuatros del siglo xx, el acontecimiento es madrileño, aunque Barcelona desempeña un papel cultural y político de primera magnitud, y en las décadas de 1920 y 1930 produjo un efecto de bipolarización que merece estudiarse.

La vocación normativa que se atribuyen los intelectuales conduce a interrogarse sobre el mismo saber, es decir, sobre la formación recibida, y luego sobre las formas y las normas de su compromiso cuando asoman como contrapoder. Parece necesario, entonces, más allá de las tendencias, de las escuelas o de las generaciones, estudiar los grupos y los individuos, así como la historia de sus ideas en las coyunturas críticas en las que estuvieron inmersos. Por consiguiente, los escritos de los intelectuales no se pueden estudiar fuera de su contexto histórico (lo cual evitaría comparar textos del joven Unamuno con discursos del Ortega maduro y, naturalmente, artículos del joven Unamuno con otros del Unamuno maduro), es decir, sin que se conjuguen las perspectivas diacrónica (el auge de un nuevo sentimiento republicano, por ejemplo) y sincrónica (frente a unos sucesos precisos).

Se ha vuelto a la cuestión del nacimiento y la reproducción de los intelectuales: cómo llegan las élites a fundar su legitimidad en la particularidad de una sociedad y frente a algunas circunstancias ( $\mathrm{Au}$ bert), y sobre los fines, las modalidades, los medios y los resultados de su compromiso en el debate ideológico, primero, y después en la vida pública.

La historia de las élites no se ha emprendido todavía según una perspectiva global y comparada sobre las estrategias de las de Europa meridional para contribuir a una sociología histórica, aunque se ha incidido de modo convincente en su participación en el relato nacional y su relación con las masas y el pueblo (Juliá), insistiendo en su 
discurso más que en su acción cuando estos no pretendieron ejercer el monopolio de la palabra autorizada sin el contrapeso de los actos reales.

Después de haber considerado la cuestión de la participación de las élites en el aparato de estado y la emergencia de élites profesionales, se cuestiona la formación de los grupos y la adquisición del reconocimiento social (memoria de las élites). El inventario del fenómeno a nivel local suele desembocar en una glosa de los estudios políticos sobre el caciquismo que Varela Ortega, Romero Maura o Tusell llevaron a cabo. No obstante, fue más fecundo el punto de vista sociológico, atento desde la década de 1980 a la emergencia y a la estructuración de las profesiones liberales (Villacorta Baños, Jordi Casassas) y del gremio de los ingenieros (Garrabou, Broder), que pusieron las bases del conocimiento de estos poderes fácticos.

Cuando las cronologías y las filiaciones parecían establecidas, nuevos enfoques y acercamientos sacudieron el estudio de las "constelaciones y generaciones». A la hora de recordar lo que se ha hecho y lo que queda por estudiar, puede ser útil dejar de querer definir lo que es o no es un intelectual (lo cual no tiene sentido, pues es una cuestión de nunca acabar) para interesarse por su cultura o su práctica social y, por consiguiente, por su confrontación con el peso de la historia y las realidades de la política o del poder, para revelar la significación y el alcance de su palabra y de su acción. Pero no separan ya la historia de lo real de la de sus representaciones, puesto que se trata de evaluar el influjo de los intelectuales sobre el curso de los acontecimientos, lo mismo que el efecto producido por estos sobre su propio itinerario. Tal ambición impone buscar una tipología propia de España, sin ser presa de los equilibrios establecidos por los mismos interesados ni de las autodefiniciones formuladas en la polémica o en una relación crítica con respecto al saber y al poder.

Más allá de las imitaciones o los desfases que afectan a las naciones, ha llegado el tiempo, en el marco de una historia ideológica y 
cultural más amplia, de considerar la oportunidad de redactar una historia cultural europea en la época contemporánea (que no excluya a España). Tras los hispanistas Alfred Morel-Fatio y Marcel Bataillon para el siglo XVII, y Jean Sarrailh para el XVIII, historiadores como Benedetto Croce, romanistas alemanes como Werner Krauss o italianos como Alberto Asor Rosa enseñaron el camino. Sin buscar una falsa analogía con la historia de los países europeos que no tienen la misma relación histórica que España con sus intelectuales, no se puede obviar un enfoque comparado, porque las similitudes políticas y los influjos ideológicos son numerosos, y cabe situar el propósito en el marco de una sociología histórica global de las élites confrontadas a la construcción de una nueva legitimidad del poder, distinta de la que se fundó en la religión, mientras se inicia en Europa un movimiento de secularización de la sociedad donde aparecen nuevos protagonistas colectivos: la burguesía industrial y el proletariado urbano.

Sin embargo, si el intelectual nacido con la revolución liberal y definido con el Affaire Dreyfus, sin duda, desapareció, ha llegado el momento de reflexionar en torno a las modalidades del surgimiento de los intelectuales del futuro (trabajo emprendido por Javier $\mathrm{Mu}$ ñoz Soro o Juan Pécourt), puesto que, a menudo, el intelectual actual mediático no es más que un fantoche utilizado por los medios de comunicación.

Copyright (C) 2019. Aquesta obra està subjecta a una llicència de Creative Commons mitjançant la qual qualsevol explotació n'haurà de reconèixer els autors, citats a la referència que apareix a l'inici del document.

Cercles. Revista d'Història Cultural, 22 (2019), 81-109. ISSN: 1139-0158. ISSN-e: 1699-7468. DOI: 10.1344/cercles2019.22.1003. 